\title{
Synthesis of highly stable luminescent molecular crystals based on (E)-2-((3-(ethoxycarbonyl)-5-methyl-4-phenylthiophen-2- yl)amino)-4-oxo-4-( $p$-tolyl)but-2-enoic acid
}

\author{
N.A. Zhestkij a, E.V. Gunina a, S.P. Fisenko ${ }^{\text {b }}$, A.E. Rubtsov ${ }^{\text {c }}$,

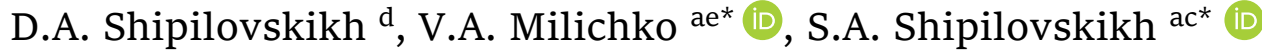 \\ a: ITMO University, 197101 Kronverksky pr., 49, St. Petersburg, Russia \\ b: A. V. Luikov, Heat and Mass Transfer Institute, NASB, 220072 Brovki st., 15, Minsk, Belarus \\ c: Perm State University, 614068 Bukireva st., 15, Perm, Russia \\ d: Perm National Research Polytechnic University, 614077 Komsomolsky pr., 29, Perm, Russia \\ e: Universite de Lorraine, CNRS, IJL, F-5400o Nancy, France \\ * Corresponding authors: v.milichko@metalab.ifmo.ru (V.A. Milichko), \\ s.shipilovskikh@metalab.ifmo.ru (S.A. Shipilovskikh)
}

This short communication (letter) belongs to the MOSM2021 Special Issue.

(c) 2021, The Authors. This article is published in open access form under the terms and conditions of the Creative Commons Attribution (CC BY) license (http://creativecommons.org/licenses/by/4.0/).

\begin{abstract}
The synthesis of

(E)-2-((3-(ethoxycarbonyl)-5-methyl-4phenylthiophen-2-yl)amino)-4-oxo-4-( $p$-tolyl)but-2-enoic acid was performed. This organic compound was used as a building block for the organic molecular crystals with highly stable photoluminescence at ambient conditions, which has been established during 10 years of exploitation.
\end{abstract}

\section{Keywords}

organic molecular crystal photoluminescence structure rigidity substituted 2,4-dioxobutanoic acids

Gewald thiophenes

Received: 09.12.2021

Revised: 14.12.2021

Accepted: 14.12.2021

Available online: 15.12 .2021

\section{Introduction}

Luminescent molecular crystals (MCs) based on organic molecules are the cornerstones of modern organic electronics and luminescent technologies. The utilization of such crystals as active components of displays and lasers [1-5] significantly decreases energy consumption and makes such devices recyclable. Generally, organic crystals (OCs) are based on organic molecules packed in a specific order, where weak intermolecular interactions maintain the integrity of the crystal structure. For such a structure, the nature of luminescence is defined by intrinsic electronic transitions of individual organic molecules and generalized electronic states, which are directly determined by the type of molecular packing [6-8].

Demonstrating unprecedented efficiency, light spectrum control [1, 3], scalability [2], flexibility [9] and enhanced time of emission (phosphorescence) [5, 7, 10-12], MCs still suffer from aging and poor structural stability $[8,11,13,14]$ at ambient conditions (in air atmosphere and room temperature). The reasons for this are, on the one hand, the violation of the integrity of the organic mol- ecules during long-term excitation. This is due to the heatand photoinduced destruction of certain chemical bonds. On the other hand, the distortion of the weak intermolecular interactions under normal conditions disrupts the aggregation of molecules and negatively affects both the emission spectrum and the luminescence efficiency $[13,14]$. What is important is that the latter effect is observed at lower excitation parameters at ambient conditions and, hence, more significantly affects the working capacity of corresponding organic devices.

\section{Experimental}

\subsection{Chemical experiments}

The yields are given for the isolated products showing one spot on a TLC plate and no impurities detectable in the NMR spectrum. The identity of the products prepared by different methods was checked by comparison of their NMR spectra.

${ }^{1} \mathrm{H}$ and ${ }^{13} \mathrm{C}$ NMR spectra were recorded at $400 \mathrm{MHz}$ for ${ }^{1} \mathrm{H}$ and $100 \mathrm{MHz}$ for ${ }^{13} \mathrm{C} \mathrm{NMR}$ at room temperature; the chemical shifts $(\delta)$ were measured in ppm with respect to 
the solvent $\left(\mathrm{CDCl}_{3},{ }^{1} \mathrm{H}: \delta=7.26 \mathrm{ppm},{ }^{13} \mathrm{C}: \delta=77.16 \mathrm{ppm}\right.$; [D6] DMSO, $\left.{ }^{1} \mathrm{H}: \delta=2.50 \mathrm{ppm},{ }^{13} \mathrm{C}: \delta=39.52 \mathrm{ppm}\right)$. The coupling constants $(\mathcal{H})$ are given in Hertz. The splitting patterns of apparent multiplets associated with averaged coupling constants were designated as $s$ (singlet), $d$ (doublet), $t$ (triplet), $q$ (quartet), sept (septet), $m$ (multiplet), $d d$ (doublet of doublets) and $b r$ (broadened). The melting points were determined with a "Stuart SMP 30», the values are uncorrected. Flash chromatography was performed on silica gel Macherey Nagel $(40-63 \mu \mathrm{m})$. The elemental analysis was performed on a Leco CHNS-932 instrument.

The reaction progress was monitored by GC/MS analysis and thin layer chromatography (TLC) on aluminum backed plates with Merck Kiesel 6o F254 silica gel. The TLC plates were visualized either by UV radiation at a wavelength of $254 \mathrm{~nm}$ or stained by exposure to a Dragendorff's reagent or potassium permanganate aqueous solution. All the reactions were carried out using dried and freshly distilled solvent.

\subsection{Synthesis of $(Z)-2$-hydroxy-4-oxo-4-( $p$-tolyl)but- 2-enoic acid 3}

A cooled mixture of $29.2 \mathrm{~g}$ ( $0.2 \mathrm{~mol})$ diethyl oxalate and $26.8 \mathrm{~g}$ (0.2 mol) 1-(p-tolyl)ethan-1-one was slowly added with stirring to a solution of freshly prepared $(0.4 \mathrm{~mol})$ sodium methoxide in $100 \mathrm{ml}$ of methanol. After one day, the precipitate that formed was dissolved in warm water $\left(60^{\circ} \mathrm{C}\right)$ and the solution was acidified with concentrated hydrochloric acid to $\mathrm{pH}=3$. The formed precipitate was filtered off and recrystallized from acetonitrile (Scheme 1).

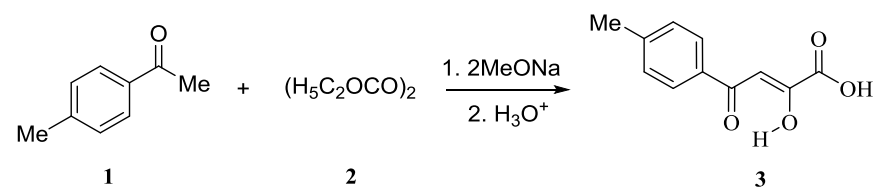

Scheme 1 Synthesis of ( $Z$ )-2-hydroxy-4-oxo-4-( $p$-tolyl)but-2-enoic acid 3

Beige crystals $(36.3 \mathrm{~g}, 88 \%)$, m.p. $141-143{ }^{\circ} \mathrm{C}(141-$ $\left.142{ }^{\circ} \mathrm{C}[15]\right) .{ }^{1} \mathrm{H}$ NMR $\left(\mathrm{CDCl}_{3}, 400 \mathrm{MHz}\right) \delta(\mathrm{ppm}): 2.48$ $(s, 3 \mathrm{H}, \mathrm{Me}), 7.16(s, 1 \mathrm{H}, \mathrm{C}=\mathrm{CH}), 7.35(\mathrm{~m}, 2 \mathrm{H}, \mathrm{HAr}), 7.94$ $\left(m, 2 \mathrm{H}, \mathrm{H}_{\mathrm{Ar}}\right) .{ }^{13} \mathrm{C} \mathrm{NMR}\left(\mathrm{CDCl}_{3}, 100 \mathrm{MHz}\right) \delta(\mathrm{ppm}): 21.8$, $94.8,128.0,129.7,129.8,145.6,161.6,174.6$. Found, \%: C 64.05, H 4.93. $\mathrm{C}_{11} \mathrm{H}_{10} \mathrm{O}_{4}$. Calculated, \%: C 64.08, H 4.89.

\subsection{Synthesis of ethyl 2-amino-5-methyl-4- phenylthiophene-3-carboxylate 6}

In a $100 \mathrm{ml}$ three-necked flask equipped with a reflux condenser, a dropping funnel, an internal thermometer and a magnetic stirrer a solution of $13.4 \mathrm{~g}(0.1 \mathrm{~mol})$ of propiophenone and $11.3 \mathrm{~g}(0.1 \mathrm{~mol})$ of ethyl 2-cyanoacetate in $40 \mathrm{ml}$ of ethanol was placed. To the resulting solution $3.2 \mathrm{~g}$ (0.1 mol) of finely ground sulfur was added. While stirring, $4 \mathrm{ml}$ of morpholine was added dropwise to the resulting mixture, making sure that the reaction mixture did not overheat. After the end of the exothermic reaction, the mixture was heated in a water bath until the sulfur was completely dissolved. After cooling the solution to $\mathrm{O}^{\circ} \mathrm{C}$, ethyl 2-amino-5- methyl-4-phenylthiophene-3-carboxylate precipitated in the form of yellow crystals. The resulting product was filtered off and recrystallized from methanol (Scheme 2).

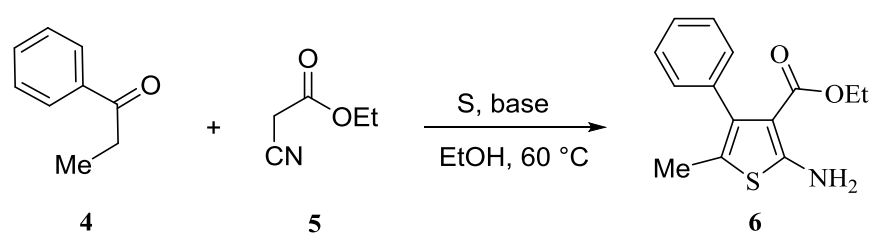

Scheme 2 Synthesis of ethyl 2-amino-5-methyl-4phenylthiophene-3-carboxylate 6

Yellow crystals $(22.47 \mathrm{~g}, 86 \%)$, m.p. $91-93{ }^{\circ} \mathrm{C}\left(93{ }^{\circ} \mathrm{C}\right.$ [16]). $\quad{ }^{1} \mathrm{H} \quad \mathrm{NMR} \quad\left(\mathrm{CDCl}_{3}, \quad 400 \quad \mathrm{MHz}\right) \quad \delta \quad(\mathrm{ppm}): \quad 1.35$ $(t, J=7.1 \mathrm{~Hz}, 3 \mathrm{H}, \mathrm{Me}), 2.3 \mathrm{O}(s, 3 \mathrm{H}, \mathrm{Me}), 4.29(q, J=7.1 \mathrm{~Hz}$, $\left.2 \mathrm{H}, \mathrm{CH}_{2}\right), 6.05\left(s, 2 \mathrm{H}, \mathrm{NH}_{2}\right), 7.29(m, 5 \mathrm{H}, \mathrm{H}$ Ar). Found, \%: C 64.30, $\mathrm{H}$ 5.72, N 5.31. $\mathrm{C}_{14} \mathrm{H}_{15} \mathrm{NO}_{2} \mathrm{~S}$. Calculated, \%: C $64 \cdot 34, \mathrm{H} 5 \cdot 79, \mathrm{~N} 5 \cdot 36$.

\subsection{Synthesis of (E)-2-((3-(ethoxycarbonyl)-5- methyl-4-phenylthiophen-2-yl)amino)-4-oxo-4-( $p$ - tolyl)but-2-enoic acid 7}

To a solution of $2.06 \mathrm{~g}$ (0.01 mol) of $(Z)$-2-hydroxy-4-oxo4 - $(p$-tolyl)but-2-enoic acid 3 in $10 \mathrm{ml}$ of ethanol was added $2.61 \mathrm{~g}(0.01 \mathrm{~mol})$ of a solution of ethyl 2-amino-5-methyl4-phenylthiophene-3-carboxylate 6 in $10 \mathrm{ml}$ of ethanol. After the resulting solution had been heated to boiling, it was refluxed. The resulting saturated red solution was kept for 24 hours at $-18{ }^{\circ} \mathrm{C}$, then the formed precipitate was filtered off and recrystallized from ethanol (Scheme 3). The compound 7 was obtained according to the previously described method [17]. The new MCs and the old MCs were obtained by the same method and repeated after 10 years.

Red crystals (3.7 g, 82\% «old MCs»), (3.6 g, 80\% «new MCs»), m.p. $171-172{ }^{\circ} \mathrm{C} .{ }^{1} \mathrm{H}$ NMR $\left(\mathrm{CDCl}_{3}, 400 \mathrm{MHz}\right)$ $\delta(\mathrm{ppm}): 0.87(t, J=7.1 \mathrm{~Hz}, 3 \mathrm{H}, \mathrm{Me}), 2.13(s, 3 \mathrm{H}, \mathrm{Me})$, $2.39(s, 3 \mathrm{H}, \mathrm{Me}), 4.00\left(q, J=7.1 \mathrm{~Hz}, 2 \mathrm{H}, \mathrm{CH}_{2} \mathrm{O}\right), 6.58$ $(s, 1 \mathrm{H}, \mathrm{C}=\mathrm{CH}), 7.20\left(m, 2 \mathrm{H}, \mathrm{H}_{\mathrm{Ar}}\right), 7.36\left(m, 5 \mathrm{H}, \mathrm{H}_{\mathrm{Ar}}\right), 7.92$ $\left(m, 2 \mathrm{H}, \mathrm{H}_{\mathrm{Ar}}\right), 12.74(s, 1 \mathrm{H}, \mathrm{NH})$. Found, \%: C 66.84, $\mathrm{H} 5.21$, $\mathrm{N}$ 3.10. $\mathrm{C}_{25} \mathrm{H}_{23} \mathrm{NO}_{5} \mathrm{~S}$. Calculated, \%: C 66.80, H 5.16, N 3.12.

\subsection{Optical experiment}

The single MCs were placed on a $6.45 \mathrm{~cm}^{2}$ (0.2 mm thickness) glass substrate under normal conditions (in air atmosphere, room temperature, and 30\% humidity). The absorption and PL spectra have been measured using a home-made confocal microscope setup $[18,19]$. The single crystals have been irradiated by incoherent (halogen light source AvaLight-HAL-S-Mini, 300-900 nm spectral range, for absorbance) and coherent light (for PL) via 100x/o.9NA Mitutoyo objective. For PL measurement, femtosecond laser system (Laser Pharos PH1-SP-20W, $1030 \mathrm{~nm}$ pump, 220 fs pulse duration, $1 \mathrm{MHz}$ repetition rate), associated with an optical parametric amplifier Orpheus HP to emit 400, 450, and $500 \mathrm{~nm}$ (with $10 \mathrm{~nm}$ band width), has been utilized. 
Me<smiles>Cc1ccc(C(=O)/C(O)=C/C(=O)O)cc1</smiles>

3<smiles>CCOC(=O)c1c(N)sc(C)c1-c1ccccc1</smiles>

6<smiles>CCOC(=O)c1c(N/C(=C/C(=O)c2ccc(C)cc2)C(=O)O)sc(C)c1-c1ccccc1</smiles>

7

Scheme 3 Synthesis of (E)-2-((3-(ethoxycarbonyl)-5-methyl-4-phenylthiophen-2-yl)amino)-4-oxo-4-( $p$-tolyl)but-2-enoic acid

The PL signal was collected in the reflection regime via the same objective and then analyzed using a confocal Raman Spectroscopy system HORIBA Labram with $600 \mathrm{~g} / \mathrm{mm}$ diffraction gratings and a water-cooling camera ANDOR. The absorption spectra $A$ for the single crystals have been obtained in the transmission regime by transmission $T$ spectroscopy $(A=1-T)$ under the assumption that signals reflected from the crystal surface and scattered on its defects were small compared with the transmission signal.
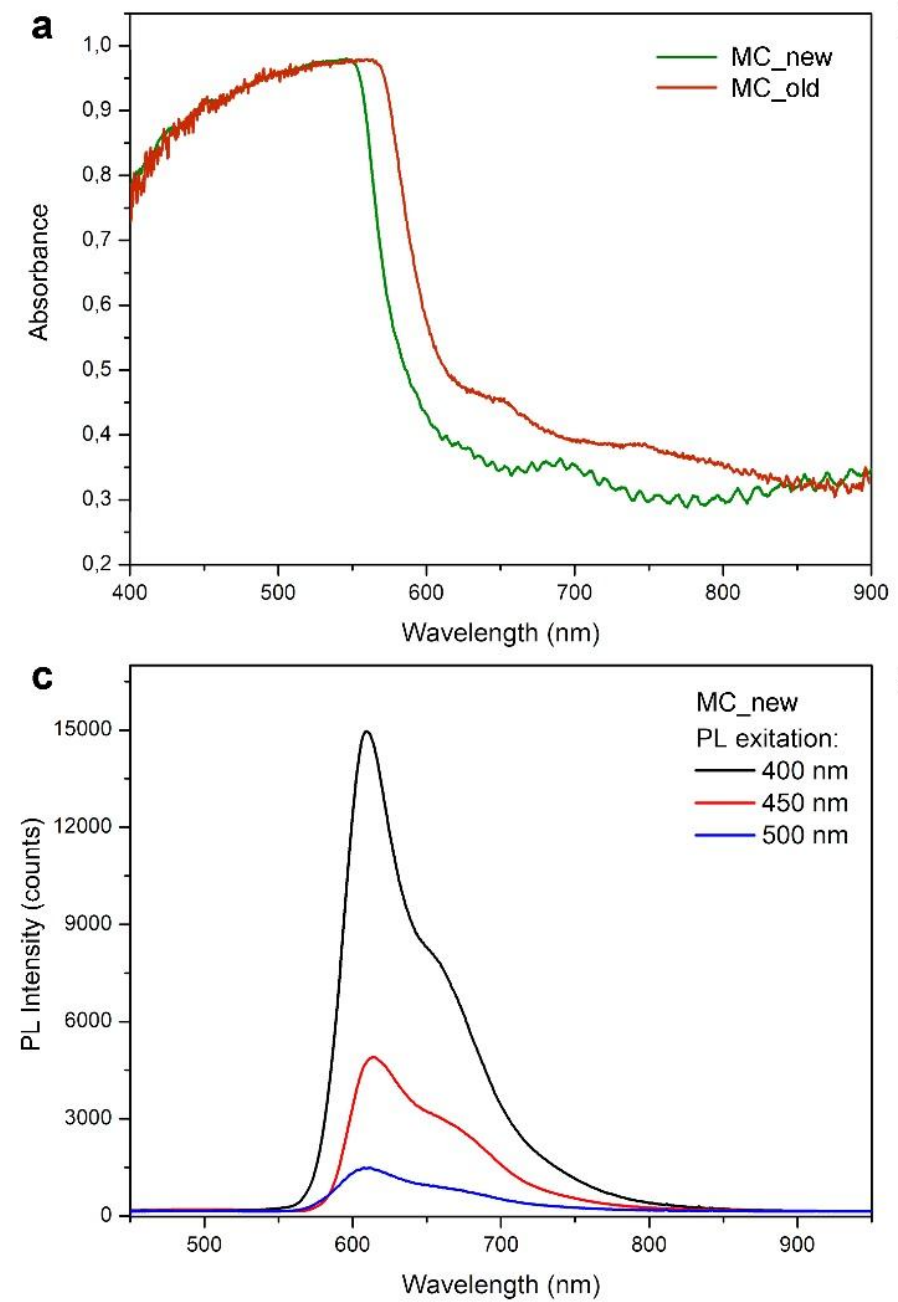

\section{Results and discussion}

Here we demonstrate the synthesis of a highly luminescent MCs based on (E)-2-((3-(ethoxycarbonyl)-5-methyl-4phenylthiophen-2-yl)amino)-4-oxo-4-( $p$-tolyl)but-2-enoic acid. The photoluminescent (PL) behavior of the old crystal has been verified over 10 years at ambient conditions. We discovered that aging of the crystals is accompanied by a $30 \mathrm{~nm}$ red shift of the absorption spectrum, while the shape and PL peaks positions have not changed after 10 years.

b
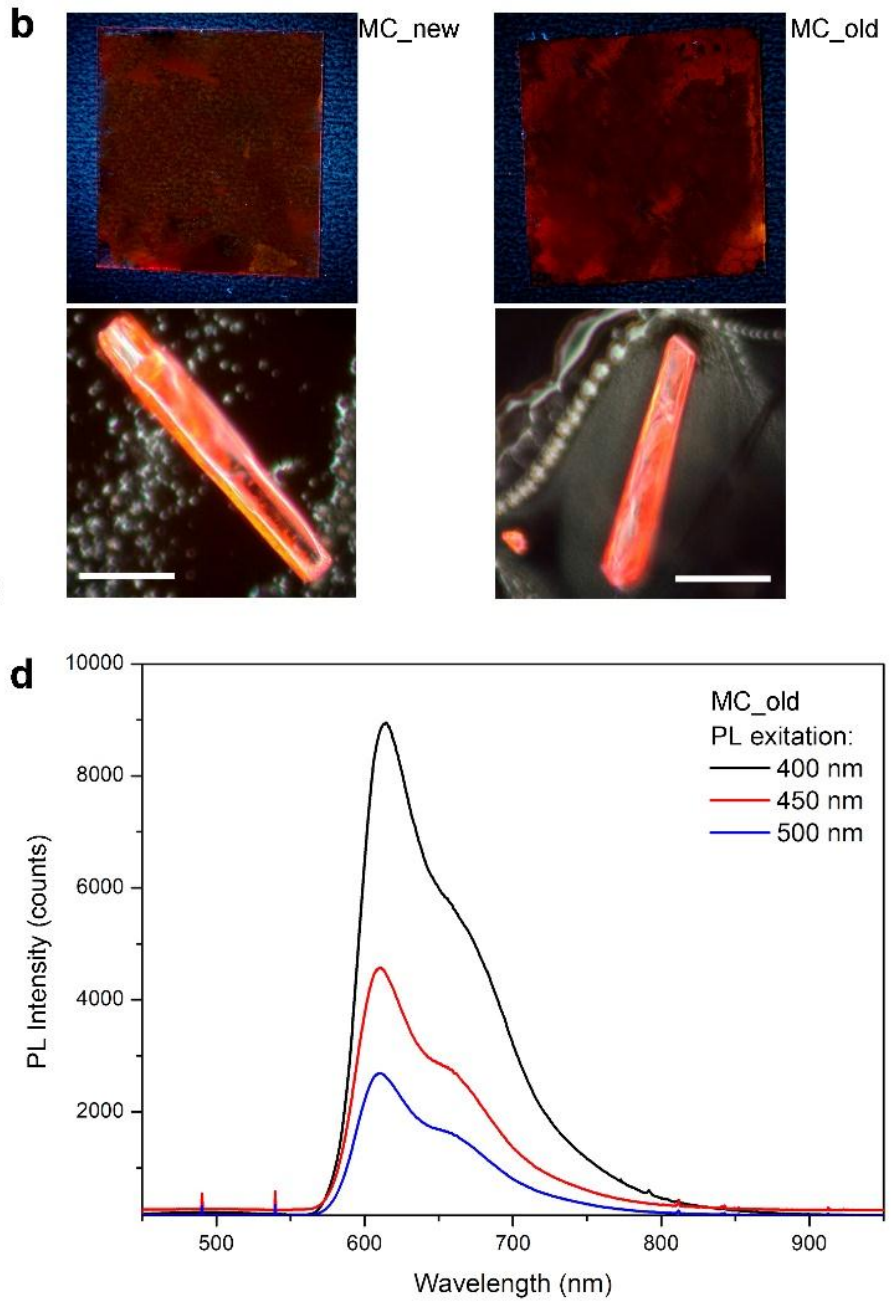

Fig. 1 The absorption spectra for single MCs (a); optical images of the corresponding single MCs and PL images of the corresponding thin films on 1 inch $^{2}$ glass, excited by $400 \mathrm{~nm}$; scale bars, $100 \mu \mathrm{m}$ (b); PL spectra for MC_new and MC_old compounds excited by 400 , 450 and $500 \mathrm{~nm}$ with corresponding $0.25,1.5$ and $2 \mu \mathrm{W}$ laser power (c, d) 
The observed decrease in PL intensity by 30\% can be explained by an enhanced self-absorption effect. Also, an analysis of PL signal versus pumping wavelength (40o to $500 \mathrm{~nm}$ ) showed an increase in efficiency when the aged crystal was excited with a green light. These results pave the way for utilization of new MCs based on (E)-2-((3(ethoxycarbonyl)-5-methyl-4-phenylthiophen-2-yl)amino)-4oxo-4-( $p$-tolyl)but-2-enoic acid as promising extended-life materials for optical application under normal operating conditions.

The optical analysis of the MCs is summarized in Fig. 1 in detail. As one can see, aging caused a $30 \mathrm{~nm}$ red shift in the absorption spectrum (Fig. 1a) and the disappearance of small interference beats for approximately the same MC thickness. This process can be described by a partial violation of the long-range order in the crystal, which can cause an increase in absorption in the red region of the spectrum [20]. However, the shape of the PL spectrum and the positions of the peaks ( 610 and $660 \mathrm{~nm}$ ) during aging were found to remain the same. This indirectly indicates both the molecular nature of the PL and the relative stability of the molecules packed in the MCs over time. In this case, the aging process is described by an approximately $30 \%$ decline in the integral PL intensity and a relative increase in the red tail by $10 \%$ (Fig. 1C, d). Also, we found that aging of the MCs causes a threefold increase in the intensity of PL excited by $500 \mathrm{~nm}$ (blue curves in Fig. 1c, d). This effect can be also explained by a red shift of the absorption band and, hence, an increase in the absorption coefficient for the old MC. Finally, the PL signal has been stimulated by extremely low laser power (0.25 $\mu \mathrm{W}$ for 400 $\mathrm{nm}, 1.5 \mu \mathrm{W}$ for $450 \mathrm{~nm}$, and $2 \mu \mathrm{W}$ for $500 \mathrm{~nm}$ ) and observed up to $0.5 \mathrm{~mW}$, confirming the MC structure rigidity with a change in the pump laser power by three orders of magnitude.

\section{Conclusions}

As a result, we report on the synthesis of $(E)-2-\left(\left(3^{-}\right.\right.$ (ethoxycarbonyl)-5-methyl-4-phenylthiophen-2-yl)amino)4-oxo-4-( $p$-tolyl)but-2-enoic acid. This organic compound was then utilized to create new organic molecular crystals in the form of single microcrystals and large scale thin films demonstrating highly efficient and stable photoluminescence at ambient conditions. Moreover, the structure rigidity allows providing the PL signal for at least 10 years of exploitation of MCs at ambient conditions. These results pave the way to design promising extended-life organic MCs for optical and optoelectronic applications.

\section{Acknowledgements}

The authors acknowledge financial support from the Ministry of Science and Higher Education of the Russian Federation (project № 075-15-2021-963).

\section{References}

1. Etherington MK. Thermally activated delayed fluorescence: beyond the single molecule. Front Chem. 2020;8:716. doi: $10.3389 /$ fchem.2020.00716

2. Gu L, Shi H, Bian L, Gu M, Ling K, Wang X, Ma H, Cai S, Ning W, Fu L, Wang H, Wang S, Gao Y, Yao W, Huo F, Tao Y, An Z, Liu X, Huang W. Colour-tunable ultra-long organic phosphorescence of a single-component molecular crystal. Nat Photonics. 2019;13(6):406-411. doi:10.1038/s41566-019-0408-4

3. Ha JM, Hur SH, Pathak A, Jeong J-E, Woo HY. Recent advances in organic luminescent materials with narrowband emission. NPG Asia Mater. 2021;13(1):53.

doi:10.1038/s41427-021-00318-8

4. Zhao H, Zhao Y, Song Y, Zhou M, Lv W, Tao L, Feng Y, Song B, Ma Y, Zhang J, Xiao J, Wang Y, Lien DH, Amani M, Kim H, Chen X, Wu Z, Ni Z, Wang P, Shi Y, Ma H, Zhang X, Xu JB, Troisi A, Javey A, Wang X. Strong optical response and light emission from a monolayer molecular crystal. Nat Commun. 2019;10(1):5589. doi:10.1038/s41467-019-13581-9

5. Zhao W, He Z, Tang BZ. Room-temperature phosphorescence from organic aggregates. Nat Rev Mater. 2020;5(12):869885. doi: $10.1038 / \mathrm{s} 41578-020-0223-\mathrm{Z}$

6. Hochstrasser RM. The luminescence of organic molecular crystals. reviews of modern physics. 1962;34(3):531-550. doi:10.1103/RevModPhys.34.531

7. Rangel T, Rinn A, Sharifzadeh S, da Jornada FH, Pick A, Louie SG, Witte G, Kronik L, Neaton JB, Chatterjee S. Low-lying excited states in crystalline perylene. Proc Natl Acad Sci. USA. 2018;115(2):284-289. doi:10.1073/pnas.1711126115

8. Yang J, Zhen X, Wang B, Gao X, Ren Z, Wang J, Xie Y, Li J, Peng $\mathrm{Q}, \mathrm{Pu} \mathrm{K}, \mathrm{Li} \mathrm{Z}$. The influence of the molecular packing on the room temperature phosphorescence of purely organic luminogens. Nat Commun. 2018;9(1):840. doi:10.1038/s41467-01803236-6

9. Huang K, Song L, Liu K, Lv A, Singh M, Shen K, Shen J, Wang J, Wang H, Shi H, Ma H, Gu M, Sun G, Yao W, An Z, Huang W. Elastic organic crystals with ultralong phosphorescence for flexible anti-counterfeiting. Flexible Electronics. 2021;5(1):21. doi: $10.1038 /$ s41528-021-00117-9

10. An Z, Zheng C, Tao Y, Chen R, Shi H, Chen T, Wang Z, Li H, Deng R, Liu X, Huang W. Stabilizing triplet excited states for ultralong organic phosphorescence. Nat Mater. 2015;14(7):685-69o. doi:10.1038/nmat4259

11. Jinnai K, Kabe R, Lin Z, Adachi C. Organic long-persistent luminescence stimulated by visible light in p-type systems based on organic photoredox catalyst dopants. Nat Mater. 2021. doi:10.1038/s41563-021-01150-9

12. Xie Z, Zhang X, Wang H, Huang C, Sun H, Dong M, Ji L, An Z, Yu T, Huang W. Wide-range lifetime-tunable and responsive ultralong organic phosphorescent multi-host/guest system. Nat Commun. 2021;12(1):3522.

doi: $10.1038 / \mathrm{s} 41467-021-23742-4$

13. Najafov H, Lee B, Zhou Q, Feldman LC, Podzorov V. Observation of long-range exciton diffusion in highly ordered organic semiconductors. Nat Mater. 2010;9(11):938-943. doi: $10.1038 /$ nmat2872

14. Takeda M, Matsui J, Masuhara A. Aging effect on the cocrystallization behavior of the donor and acceptor crystals in aqueous dispersions. Mater Adv. 2021;9(2)2935-2942. doi:10.1039/DoMA01001D

15. Sof'ina OA, Igidov NM, Koz'minykh EN, Trapeznikova NN, Kasatkina YS, Koz'minykh VO. Reactions of Acylpyruvic Acids and 2,3-Dihydrofuran-2,3-diones with 2,3-Diaminopyridine. Russ J Org Chem. 2001;37(7):1017-1025. doi:10.1023/A:1012438902959

16. Moeinpour F, Dorostkar N, Vafaei M. Mg/La mixed oxide as an efficient heterogeneous basic catalyst for synthesis of 2aminothiophenes under microwave irradiation. Synth Commun. 2012;42(16):2367-2374. doi: $10.1080 / 00397911.2011 .557175$ 
17. Shipilovskikh SA, Makhmudov RR, Lupach DY, Pavlov PT, Babushkina EV, Rubtsov AE. Synthesis and analgesic activity of substituted 4-(Het)aryl-4-oxo-2-thienylaminobut-2-enoic Acids Pharm Chem J. 2013;47(7):366-370. doi:10.1007/s11094013-0960-Z

18. Milichko VA, Makarov SV, Yulin AV, Vinogradov AV, Krasilin AA, Ushakova E, Dzyuba VP, Hey-Hawkins E, Pidko EA, Belov PA. Van der Waals metal-organic framework as an excitonic material for advanced photonics. Adv Mater. 2017;29(12):1606034. doi:10.1002/adma.201606034
19. Kulachenkov NK, Sun D, Mezenov YA, Yankin AN, Rzhevskiy S, Dyachuk V, Nomine A, Medjahdi G, Pidko EA, Milichko VA. Photochromic Free MOF-Based Near-Infrared Optical Switch. Angew. Chem Int Ed Engl. 2020;59(36):15522-15526. doi:10.1002/anie.202004293

20. Ito F, Suzuki Y, Fujimori J, Sagawa T, Hara M, Seki T, Yasukuni R, Lamy de la Chapelle M. Direct visualization of the twostep nucleation model by fluorescence color changes during evaporative crystallization from solution. Sci Rep. 2016;6:22918. doi:10.1038/srep22918 